\title{
Historical view of the damage caused by the 1693 Catania earthquake and the reconstruction activities
}

\author{
D. Ligresti $^{1} \&$ S. Grasso ${ }^{2}$ \\ ${ }^{1}$ Department of Political Studies, University of Catania, Italy \\ ${ }^{2}$ Department of Civil and Environmental Engineering, \\ University of Catania, Italy
}

\begin{abstract}
Eastern Sicily (Italy) is one of the areas at highest seismic risk in Europe, and its long history (2700 years from the Greek settlements to the present) enables scientists to access a vast amount of data related to geophysical and geotechnical characteristics, both complex and diverse relationships that are established over time between the disaster and the human communities that will suffer. The recognition of change, or the lack of change, that repeated catastrophic events in an area makes to the culture (science, technical, religious, administrative) and the attitudes of groups of people who remain, are the basic elements for building a complex model to understand the catastrophic phenomenon, which combine different disciplines and specializations, in order to compare experiences in different areas and at different times. The methodological problem, of which scientists who collaborate on the study of disasters have long been aware, is to connect the earthquake with the historical and anthropological understanding of the earthquake, to develop a "culture of earthquakes" that operates in the direction of the scientific organization of cities and housing in seismic features. The aim of this paper is to highlight some of these "elements" through the observation of historical earthquakes in south-eastern Sicily, and particularly in Catania during the catastrophic events of 9 and 11 January 1693, with the goal of providing a key to the cultural and social situations that are also present.
\end{abstract}

Keywords: historical view, 1693 Catania earthquake, Val di Noto, reconstruction activities. 


\section{Introduction}

Strong earthquakes that affected this area in the medieval and modern ages took place in 1169 (X MCS), 1542 (X MCS) and 1693 (XI MCS), but quite frequent were those of VI-VIII degree MCS, which caused dozens of casualties and heavy damage. Therefore, as a part of research programs, Italian Projects have been developed to design a map of seismic risk, paying particular attention to this area from a purely seismological viewpoint. To assist in this, a catalogue of strong earthquakes in Italy from 461 B.C. to 1990 A.D. has been compiled [3]. The complexity of the phenomenon earthquake has, however, resulted in the activation of various scientists of other disciplines to collaborate with scientists of various specialties, who have already conducted an excavation of the sources and the publication of individual or miscellaneous works that have highlighted the many and varied aspects of the event [4-6], and it now appears possible to identify essential parameters for understanding the phenomenon of catastrophic events in Sicily in the seventeenth century, taking into account the advanced studies of volcanology.

\section{The theoretical and philosophical knowledge of seismic phenomenon from ancient times to the seventeenth century}

The earthquake is one of the founding myths of European culture, and is also among the first objects of study in philosophy and science. Greek and Latin philosophy analyzed the earthquake as a natural phenomenon and the foundation of the interpretive paradigm of most successful and longest duration was due to Aristotle, for which the earthquakes were caused by "dry exhalations" enclosed within the earth seeking a violent way out. In the mid-seventeenth century in Sicily, the seismic interpretations of the phenomenon were not different from those which may have occurred in different European countries: a) predominance of the religious concept of the disaster as divine punishment in the collective mind; b) acceptance of the Aristotelian-scholastic theory with several subsequent updates by the philosophical culture, a position that could integrate with the former on the basis of the distinction between the St. Thomas causa prima ("prima causa est voluntas Dei") and causa seconda ("mediante causis secundis hoc agit") entrusted with the laws of nature; c) diffusion in some environments (University of Messina) of new scientific general theories (Agricola, Galileo, Descartes) and especially of the discussions on volcanism and underground fires, here reported by Alfonso Borelli (De vi percussionis) making a possible explanation of the seismic phenomena and defining the mechanical foundations of the law of elastic bodies. From a practical point of view, although earthquakes were observed, studied and classified, there was no transfer of this debate when technological solutions were aimed at introducing defensive construction. 


\section{Local seismic culture and general prevention of the risk of earthquake}

Some attempt to read about the technique and the static elastic response of a structure to dynamic stress testing and subsequent construction (the intuitive concept of structural frames according to seismology and the use of arms wedges mixed) can be found since ancient times in the work by the architects and engineers, but it was based on fundamentally vague mechanical observations combined with the religious element [7].

Technical knowledge was, however, applied only to public buildings, such as the Theatre in Catania, the Odeon, the Amphitheatre (sophisticated testing), while housing remained basic and essential. In the tradition of construction there are two main types of anti-seismic structures: a) a combination of frame and stone tannage filling material spans unstructured buildings (opus africanum), b) mixed. From a practical point of view it may be said that the need for special technical solutions to protect buildings from earthquakes was known, but there were no special laws for economic reasons and most of the buildings were built with no criteria taking particular account of this eventuality.

\section{Transmission of the earthquake's memory: devotion, literature, administration and military defence}

The disinterest of the authorities and the commissioners themselves to the deployment of some additional proof was given by the earthquake as an event of exceptional circumstances as envisaged by the gods for retribution or warning, and therefore humanly unchallenged. The prevalence of the religious interpretative model entailed a mode of transmission writing of the seismic entrusted mainly to two types of texts, chronicles and an apology. If for publication, both tended to enrich the story of extraordinary items, unusual, miraculous, and quite free to interpret the number of casualties and damage, to win the goodwill of the reader with rhetorical devices and literary or religious references.

The authors of the reports, chronicles and stories, are of all classes to medium-high or the clergy. However, it is possible to see that often in the same report events, there are different points of view, as is evident in the two chronicles of Grammichele written after 1693: the first, written by a 'jury' in charge, aims at demonstrating the social cohesion of the community, its work, the speed of decisions and solutions that are contracted with the feudal lord, and the other, probably written by a religious framework, draws the opposite response of being terrified and prostrate, instead receiving comfort from devotional and religious practices and accepting the decisions of the feudal lord as providential [8].

However, in Sicily since early times there has always been a scientific curiosity to investigate the phenomena of nature and an interest in science, as is the tradition of local pluriminnelaria, and this has created and consolidated the presence of bureaucratic and technical classes in analytically describing a 
catastrophic event focussing on the characteristics of collapsed or damaged structures, technical surveys on the causes and how that led to such damages and on financial analysis of the costs of reconstruction. The archived documents record disaster survivors and the destructive action of men, yet it is not difficult to find traces of texts of a different nature: private chronicles written by professionals and notaries with narrow adherence to reality, administrative reports made by a 'jury' to highlight the damage and cost of repairs and scientist's direct observations of events (Filoteo of Omodei [9] described the Etna eruptions of the years 1536-37 and went in person twice to the top of the crater to measure any changes).

The practical effect of this interest is not reflected in concrete measures, but probably worked in the long term within the various government departments and administrations and certainly paved the cultural turn of post-1693. One area, however, is certainly significant: military engineering. Sicily became antimurale and bastion of Christianity against the Turkish between the last forty years of the sixteenth century and the first decades of the seventeenth century and turned into an island-fortress. The entire system was redeveloped to fit fortified defensive use of firearms, the city was fortified, a belt of over a hundred coastal warning towers was devised and the city was defended against the incursions of enemies and pirates. This system was implemented by engineers from all parts of the empire, which continued to impose inspections, reports, reviews and restructuring: Ferramolino from Bergamo, Siena Tiburzio Spannocchia, the Florentine Cammillo Camilliani, Dutch Carlos de Carlos Grunenbergh and the Lombard Joseph Formenti. Observations, reports, speeches, studies and projects that revolved around this activity were, inter alia, the practical effect of keeping up to date knowledge of engineering and urban planning in Sicily in line with European higher levels [10].

\section{$5 \quad$ Traditions and building types}

The type of settlement that has always characterized the people of Sicily since ancient times has seen the prevalence of the urban community, as can be defined in different eras. In particular, since the Muslim destruction of habitat by the Normans and the Swabians, the majority of the population lived in Sicilian population centres with more than $2,000,5,000$ or 10,000 inhabitants. The percentages shown in table 1 are derived from Sicilian census data from 1542 and in 1681 .

Table 1: Resident population in Sicily ordered size of population centre (percentages) [11].

\begin{tabular}{|l|r|r|r|r|r|l|}
\hline & $<2000$ & $2000-$ & $5000-$ & $10000-$ & $>50000$ & \\
& & 5000 & 10000 & 50000 & & \\
\hline 1548 & 8,20 & 31,21 & 27,21 & 24,79 & 8,60 & 100,00 \\
\hline 1681 & 10,80 & 25,36 & 29,00 & 19,10 & 15,74 & 100,00 \\
\hline
\end{tabular}


The built heritage of the towns of eastern Sicily was accordingly constituted by a series of urban layers accumulated during centuries of emergencies (Catania, Siracusa), Arab quarters, fortifications and old settlements Norman Swabian (Ursino Castle in Catania), Aragoneses extensions (the Catania neighbourhoods of Civita and Ursino), new extensions that caused the growth of settlements (houses in Etnea) and restructuring during the seventeenth century after the great eruption of 1669 that came up at the port of Catania. The soil was of a different nature (in some areas bedrock, sandy or clay in others). The simple houses of the slums (the home studio or one bedroom apartment with a courtyard earth prospectus) were constructed with materials that were often second-hand; without great shrewdness, there were more complex structures and then gradually more stable homes (lava rock) of the noble and professional classes, and public buildings of worship, structures and manufacturing crafts, which also vary in age and type.

Many of these features constitute in themselves an effect of seismic risk and the negative effects of an earthquake: urban overcrowding, and dilapidated old houses sometimes abandoned alongside those that are new and better structured, neighbourhoods with small, winding roads, blind alleys, limited and small open areas, lack of rules and planning or at least limited effect of building regulations issued that began early in the fifteenth century (in Catania in 1412). On the whole we can say that despite the theoretical analysis of seismic phenomena and the existence of building techniques that when adopted could reduce their devastating effects, in 1693 the urban structure of the Sicilian community did not take account of these risks in almost any way.

In 1693 this situation led to disastrous casualties and damage in a wide area, but it is important to note that the first shock of January 9 was much less disastrous, and that the severity of the damage caused by the later and more powerful shock on January 11 was largely caused by previous damage, plus the inadequate behaviour of the people who went on the sites affected after 24 hours.

\section{The Val di Noto earthquake of 1693}

The Val di Noto earthquake of 11 January 1693, associated with the previous shock of January 9 (VIII-IX degree MCS) and the subsequent tsunami, is with the Messina earthquake of 1908 the largest event of catastrophic dimensions affecting eastern Sicily in historical times and was absolutely the most intense earthquake ever recorded in the Italian territory, with a magnitude equal to 7.4 and affected an area with seismic effects VIII-XI MCS degree approximately equal to $14,000 \mathrm{~km}^{2}$. The earthquake caused the destruction (in Catania, Noto, Sortino, Acreide Palazzolo, Scicli, Modica, Melilli, Lentini, Carlentini and Occhiolà) of all or part of the towns of Val di Noto, hitting a total of 70 locations with equal or greater damage to the IX MCS and causing a total of about 60,000 deaths among those who perished under the rubble (54,000 according to an official report) and those that occurred in the following months due to injuries or health conditions [12]. In Catania 11,964 victims were recorded among a population of 18,914 inhabitants. 


\section{The reactions to the disaster}

151 years after the disaster, and some similar events in 1542, the scenario changes dramatically and even overturns. It seems that all the theories, observations, experiences, news, stories and discussions about earthquakes of the past, which thus had little effect on the practice of prevention, suddenly brought in a new dimension of the response to seismic events. This sudden difference between the past and the present may in part be explained by the progress of knowledge and the expansion and strengthening of the 'modern' central authority, but in relation to the psychological and perceptual factors that determine the sudden slowdowns and accelerations in the prevention of disasters today. The first obvious difference is the response of state and local authorities, religious and feudal by their immediate presence and effectiveness. The second difference is the present mentality of a statistical-quantitative nature and therefore in the implementation of procedures for information to accurately determine the number of victims, injured and damage to religious buildings, public and private sectors and an initial analysis of costs of reconstruction.

The third difference is affirming the concept of public assistance compensation to survivors, suspended for a decade due to government taxes, fees designed (by 'purpose'), the use of the tenth due to the Pope for the reconstruction of religious heritage etc. Following this there is the significant change in legal proceedings to ensure transparency and clarity in a series of decisions involving the fate and lives of people, places and cities themselves, with the transition from the concept of immutability and invariance of the right to conception of the variability of positive law, a process through which legal systems became autonomous in relation to social relationships and interdependence in which decisions are substantially complied with and accepted by inhibiting the action of armed violence of faction or class. This leads to an address of great importance for the future because the law is part of the preconditions of the capacity of response (by providing an appropriate framework of standards for the management of the crisis) among all of the elements that make up the "crisis management" [13].

\section{The reconstruction: preventing construction}

The decision-making process in the hands of the government extraordinary commissioners must then return within the normal institutional life and the various bodies. The problems are many and varied: the reconstruction site, the urban plan, finding the necessary resources, the comparison of the social body and established power or between communities and feudal lords, the control of population flows and the fundamental resource of the workforce. Decisions are required to be clear, timely, and find general consensus. It appears, however, for the first time in a coherent and purposeful awareness, that it is necessary to plan before the repetition of catastrophic events in terms of prevention, calculating and risk reduction. Finally it seems clear that in order to present effective 
methods it is necessary to know as much as possible about the nature of the earthquake and how the shocks are reflected and propagate on the surface.

The answers come in all three areas: governance, prevention and research. Apparatuses are changed and laws and procedures are made appropriate to respond to disastrous events. During the earthquake of January 11 many died while fleeing in the streets that were too narrow, which precipitated the buildings that were destroyed; the new urban fabric was designed bearing in mind that Catania was subject to violent seismic events: the streets should have a width of more than 8 meters, the majority of which have a width of 16 meters: the two orthogonal axes on which the new roads and other major roads were designed has a width of 12 meters. None of the roads could be less than 4 meters wide. The number of squares was increased and expanded and extensions were designed for a system of squares in the tight space.

The determination of the "plant" urbanism and its strict observation becomes a kind of obsession that affects everyone. The feudal lord of one of the destroyed, Prince Carlo Maria Carafa, for example, designed the extraordinary architectural plan of the new Occhiolà, renamed Grammichele, Renaissance city was "ordered" based on the scientific principles of geometry. No rules were established for greater safety of the buildings, but it amounted to a kind of "social control" in the work of manufacturers.

\section{Attitudes and science}

Meanwhile, the collective mentality abandoned the belief in the catastrophic event of the supernatural as hostile (as is the case for trial on the plague) and realized the gap with a mindset rooted tenaciously in the sacral and remained unchanged for centuries. The philosophy, from which science started to distinguish itself as an autonomous field of knowledge, multiplies the attempts to explain a unified theory of the earth trembling and began to ask questions about the psychological effects and health problems affecting individuals after such a trauma. Domenico Bottone, in De Immani Trinacriae Terraemotu Idea Historico-Physica, describes the physical and medical effects of the earthquake, describing the conditions derived, indicates the impact on the individual and collective psychic.

In the wake of continuous renewal already begun, the search for causes of earthquakes continued to analyze the effects on the surface, although this did not go to the eighteenth century beyond the theories of internal combustion ("fireman"), which are the opposite supporters of the thesis that will be generated from electrical discharges ("electricians"). One reason could be that it is prudent to address the first tentative finding of shelter against the mournful event, which led to experiencing new building techniques: the capacity of resistance of humble materials such as wood, the ability of various materials to resist the vis percussionis. The suggestions could also emerge from ancient treaties: the Architecture of Vitruvius in the Treaty of Architecture of Filarete, from the Idea of Universal Architecture of Scamozzi or from Aedificatoria Re of Leon Battista Alberti [14]. 
In Noto the use of an ellipsoidal timber section, suitable for including in factories to support themselves, is included. This technique, with clear proof shrewdness, was probably made with the importing of calabrese timber (noted from the archival documents [15]).

\section{Conclusions}

Apart from the pestilence and famine that belong to other types of phenomena, and the fire of London in 1666, the Sicilian earthquake of 1693 is the first catastrophic seismic event in the world that can be studied and analyzed in depth for the amount of contemporary evidence and the quality and complexity of the reactions triggered in many areas. This, and the next largest earthquake that destroyed Lisbon in 1755, constitute the fundamental basis for a study of disaster management to address the diachronic dimension and may indicate essential aspects of both cultural and technological-scientific understanding of human response to disasters.

\section{References}

[1] Giarrizzo, G., Aymard, M., 2007. Catania. La città, la sua storia, a cura di Giarrizzo, G. e Aymard, M. vol. I, Catania 2007.

[2] Ligresti, D. 1995. Catania e i suoi casali, Catania 1995.

[3] Boschi, E., Guidoboni, E., Ferrari, G., Valensise, G., Gasperini, P., 1997. Catalogo dei forti terremoti in Italia dal 461 a.C. al 1990. In: Faccioli E., a cura di, 1999, The Catania Project: studies for an earthquake scenario, "Journal of Seismology", 3, n.3, special issue.

[4] Giarrizzo, G. 1996. La Sicilia dei terremoti. Lunga durata e dinamiche sociali, Catania 1996.

[5] Ligresti, D. 1992. Terremoto e società in Sicilia (1501-1800), Catania 1992.

[6] Dufour L., Raymond, H. 1693. Val di Noto, la rinascita dopo il disastro, Catania 1994.

[7] Tomasello, F. 1996. Edilizia antica e sismi, struttura muraria del tipo a telaio in Sicilia, in La Sicilia dei terremoti, pp. 21-30.

[8] Rota, G. 1996. Brevi considerazioni su due cronache del terremoto del 1693 a Occhiolà, in La Sicilia dei terremoti, pp. 241-254.

[9] Curti, C., Clausi, B. 2009. Filoteo degli Omodei, Aetnae topographia, di C. Curti e B. Clausi, Catania 2009.

[10] Ligresti, D. 1993. L'organizzazione militare del regno di Sicilia (15751635), in "Rivista storica italiana", anno CV, III (1993), pp. 647-678.

[11] Ligresti, D. 2002. Dinamiche demografiche nella Sicilia moderna (15051806), Milano 2002, p.196.

[12] Guidoboni, E., Ciuccarelli, C., Mariotti, D. 2001. Catania alla fine del Seicento e i terremoti del gennaio 1693, in Catania terremoti e lave, pp. 105-166. 
[13] Luminati, M. 1996. Noto 1693-1703: superamento della crisi e processi decisionali. La dimensione giuridica, in La Sicilia dei terremoti, pp.283296.

[14] Dollo, C. 1996. Vulcanismo e terremoti nei neoterici siciliani del XVII secolo, in La Sicilia dei terremoti, pp. 199-224.

[15] Guzzardi, L. 1996. Il sito delle Meti. Preesistenze e sopravvivenze nella nuova Noto, in La Sicilia dei terremoti, p. 269. 